Mills, M., Monk, S. Keddie, A., Christie, P., Renshaw, P., Geelan, D. \& Gowlett, C. (Forthcoming). Differentiated learning: From policy to classroom. Oxford Review of Education.

\title{
Differentiated learning: From policy to classroom
}

\section{Introduction}

Michael Power (1999) has suggested that those located in the UK, and many comparable countries, live in an 'audit society'. He suggests that the 'audit' has come to shape much of social, organisational and political life, and that audits are no longer simply concerned with financial matters. Across many fields, for example, health, social services, public service bureaucracies, higher education, and of course school education, vast numbers of people have been employed to monitor and verify the accounts that others provide about the quality of their work. Much has been written about the ways in which schools and teachers have been increasingly regulated through this 'audit culture' (Ball, 2012; Lingard, 2010; Perryman, 2006). Integral to this culture are various reporting and school assessment frameworks (OfSTED'), testing regimes (NAPLAN ${ }^{i i}$, PISA ${ }^{\text {iii }}$ ) and public representations of data (newspaper league tables, government websites ${ }^{\text {iv }}$ ). Whilst these measures have ostensibly been implemented to improve the quality of education experienced by students, it has been noted that they often have 'perverse effects' in that they work against such improvement (Lingard \& Sellar, 2013; Stobart, 2008). In this paper we consider the effects of a government initiative in the Australian State of Queensland to introduce a Teaching and Learning Audit of all government schools. We then focus on one aspect of this audit, the extent to which schools have been deemed to meet the requirements of 'differentiated classroom learning', and the implications of measuring such practice in schools. We then explore the effects of one school's attempts to meet the department's requirements in this area. We would suggest that given the 'policy borrowing' that occurs across nations of the global North (we would include Australia here) (Lingard, 2010), the 
lessons of how this particular audit was implemented in schools have purchase outside of that country. Indeed, we note that in England, one of the standards that teachers have been expected to meet since September 2012 is the ability to 'differentiate appropriately' (DfE, 2010, p.8).

The paper draws on data collected from Red Point High School ${ }^{\vee}$, one of the state's 1257 schools and education centres audited in 2010. This large regional school primarily catered to students from middle class backgrounds. The school received a rating of medium (the report card equivalent of 'could do better') on differentiated learning in the audit. This was the lowest ranking on the school's audit report. After the Teaching and Learning Audit results were made public, the case study school engaged with academic researchers to expand on the notion of differentiation, and to implement reforms and strategies that took into account the needs of all students in the school. The research project that ensued included observations of teacher practices and interviews with teachers about the ways in which they differentiated learning in their classrooms.

We begin the paper with a consideration of the context operating in Queensland, then consider the various ways in which differentiation can be understood, and finally explore the ways in which the case study school engaged with the audit expectations to differentiate the classrooms. Data from the school indicated that teachers had not been provided with a consistent message about what is meant by differentiation; nor adequate support for implementing this policy requirement; and that the audit requirements led to increased surveillances of teachers. However, the paper suggests that some spaces were opened up by the Teaching and Learning Audit requirement to differentiate classroom learning, perhaps ironically given many of the 'perverse effects' generated by an audit culture, that could potentially support the pursuit of a social justice agenda in the school. We do not want to trivialize the impacts of an audit culture upon those working and studying in schools, but wanted to look for spaces, points of resistance, within this culture for pursuing a social justice agenda. Data from this paper also indicate that differentiation is a complex concept which is not 
easy to shift from a policy to a classroom context, and which requires more careful explication at policy level and also more support for teachers to enact. 


\section{Context}

In 2008 there was a significant outcry at Queensland's results on national standardized tests, NAPLAN, when these outcomes suggested that Queensland students in the middle primary were doing worse than those in all other Australian States and Territories except for the Northern Territory, a Territory with a very high Indigenous population. It was suggested that this could be explained by a steady decline in Queensland students' performances in junior secondary mathematics between 1964 and 1995, a decline said to be larger than in any other State (Masters 2009). In response to these claims, and others (see Masters 2009, pp. 12-35), the then Queensland Premier, Anna Bligh, commissioned the Australian Council for Educational Research (ACER) to undertake a review of education in the State. Out of the findings and recommendations of this review, an audit process was begun in Queensland and, with it, an accompanying 'Audit Instrument', created by the ACER, containing eight 'dimensions'vi by which schools could be evaluated and rated. All government schools were required to participate in the audit process as part of the school improvement agenda across the State. Introduced in 2010, the audit ranks school performance on each of the eight dimensions at one of the following levels: outstanding; high; medium; or low. Every government school has to be audited at least once every four years, but no more than once in a 12 month period, new schools are not to be audited until the second year of operation. The audits are carried out by 'experienced' school principals who visit a school over a one to two day period, depending on the size of the school, and interview staff, students and the Parents and Citizens (P \& C) Council president. Reports are then provided to the school which is required to publish the findings for the school community on its website.

The State's main newspaper, the Courier Mail, was able to access the results through Freedom of Information legislation, and published the outcomes in a league table form (Chilcott 2012). This led to an outcry by teachers, and the Queensland Teachers' Union placed temporary bans on the process. These have since been lifted. What was apparent from the Courier Mail table was that of 
the eight ranked practices, it was Differentiated Classroom Learning that was most regularly assessed as being least evident in a school.

\section{Differentiation}

Differentiated learning in this audit referred to the ways in which teachers in their day-to-day teaching addressed the needs of all their individual students, monitored their progress, identified their specific learning needs and addressed these needs in their practice (Masters, 2010, p. 14). The principal at the case study school had been a member of one of these audit teams prior to taking up his position at the school. He noted about the Queensland schools he had visited as part of the audit process:

From previous experiences working around the State and looking at Teaching and Learning Audits and the particular area around differentiation...there's been an overwhelming recognition that differentiation is not done well in school.

Part of the problem appears to be that differentiation has been variously conceived. At one level it can be seen in terms of a system, whereby there are different types of schools designed for different types of students. Current policy initiatives include selective academic academies and selective high schools where excellence and high performance are claimed to be maximized. The negative effects that this selective system has on social justice and on children from low socioeconomic and particular ethnic and racial communities has been well documented (see for example, Connell, 1996; Coldron, Cripps \& Shipton, 2010; Laitsch, 2013). Underlying this approach is an assumption that 'an intellectually homogeneous student body fosters the development of talent and enhances efficient teaching, thus improving the quality of educational outcomes' (OECD 2005 p. 48).

This assumption also underpins much of the differentiation currently occurring at the school level. Within school differentiation is most obvious in terms of distinctions made between academic and 
vocational programs. Other examples may be 'gifted and talented' programs, 'special education' classes, or the streaming of classes according to student test results or behaviour (see for example, Noble 2004; Kronborg \& Plunkett, 2008). However, differentiation can also occur at a class level, this can involve splitting the class into small groups, giving individual learning activities, or modifying curriculum materials based on perceived ability. However, differentiation can also entail a recognition of the different knowledges that various students bring to the classroom, their differing skills, and their diverse interests and circumstances, and responding in ways that value these differences and use them to engage students in the work of the classroom. This latter form of differentiation is perhaps most properly conceived of as 'pedagogical differentiation' or in US terms, 'instructional differentiation'. It is this form of differentiation that we are concerned with in this paper, and perhaps most aligns with that advocated within Queensland's Teaching and Learning School Improvement Framework (Masters, 2010). It is perhaps no surprise that the audit of schools found little evidence of differentiation, as Subban (2006, p.938) has indicated: 'Uniformity, rather than attending to diversity, dominates the culture of many contemporary classrooms'.

Carol Tomlinson has been one of the most ardent supporters of 'instructional differentiation' and was regularly cited by teachers we interviewed. Her work on differentiation spans from the mid1990s to the present (see for example, 1995; 1999; 2000; 2005; 2008). She argues that differentiation entails providing all students with challenging and safe and supportive classrooms where there is focus on disciplinary knowledges, where teachers employ a range of methods, including whole class, small group and individual arrangements, and where 'teachers use time, space, materials, and instructional strategies in flexible ways to address varied learner needs' (Tomlinson, 2005, p. 263). She also argues that classrooms need to be communities where students have their voices heard. In outlining the goals of differentiation, Tomlinson (2008) claims that teachers need to build trust in the classroom, to create an environment where the students care about the work that they are expected to undertake because it is meaningful to them and connected 
to their worlds. She also articulates a concern with democratic classrooms through her advocacy of student voice as a goal of differentiation. According to Subban (2006, p.941), in differentiated classrooms, 'Teachers should find ways to engage students, by tapping into what interests students, and by involving students in the daily running of the classroom.'

To differentiate in the ways that Tomlinson and others articulate, it becomes apparent that teachers need to know and understand their students. This includes having an understanding of the various injustices they may experience in their lives both inside and outside the school grounds. Subban (2006) in a wide ranging literature review of 'differentiated instruction' argued that contemporary classrooms characterized by diversity on a number of levels, for example, social, cultural and intellectual, require forms of pedagogy that can engage students in classwork. As such she contends that the curriculum has to be connected to their lives. This, Subban (2006, p. 941) indicates, emphasising the work of Tomlinson (2005), requires teachers to know their students, including their 'cultural links'. Reflecting the arguments related to the productive pedagogies framework (Hayes et al., 2006) that stressed the need for classrooms where difference was valued within a learning community, she claims that 'differentiated instruction supports the classroom as a community, accommodating difference and sameness.' Ginsberg (2005) argues that respecting cultural diversity and drawing upon students' cultural knowledges also increases the motivation of students who have perhaps switched off from school.

One issue that regularly raises its head is the relationship between assessment and differentiation, as indicated in the case study data below. There is some sense that whilst classrooms may take into account differences amongst learners, assessment should not be differentiated. The arguments are many. They include, for instance, that grades across a year level and subject are only meaningful if all students have undertaken the same task, that having different tasks for different students will not challenge all students intellectually; that different expectations of students reinforces the deficit construction of some, usually marginalized, students; and that students will acquire a false sense of 
their abilities. However, there are arguments which suggest that high quality assessment practice and differentiation are not incompatible (see for example, McTighe \& Brown, 2005; Moon 2005; Tomlinson, 2005). Various proponents of differentiation have outlined the synergies between the two. For example, Moon argues that three of differentiation's key principles are that learning has to be active, involve high expectations (with appropriate scaffolding) and that it should occur in a social context (Moon, 2005, 231). These are all characteristics of high quality 'authentic assessment' or 'assessment for learning' (see for example, Torrance, 1995; Newmann \& Associates, 1996; Black et al., 2003; Lingard, Mills \& Hayes, 2006; Klenowski, 2011; Swaffield, 2011). The view is that having different assessment tasks that take into account student diversity, as long as the tasks are designed to work with the same learning objectives and assessment criteria and are intellectually challenging and meaningful, is an important means of ensuring that teachers are able to 'eliminate barriers to demonstrating achievement' (Tomlinson, 2005, p.265).

In considering the relationship between assessment and differentiation there are also questions about the purposes of assessment. Regularly assessment is seen as the endpoint of a unit of work that assesses and ranks student performance. It is also sometimes seen as providing feedback to students on what their strengths are and where they need to improve. However, as much of the assessment literature cited above indicates, assessment is much more than that. It also provides important 'data' to teachers on what students know when beginning a unit of work, on what certain students need to focus on in terms of meeting the task expectations, what strategies the teacher is employing that are working and what need changing, and how these might differ for different students, and what the teacher might need to do before undertaking this particular unit of work in the future. However, as Moon (2005, p. 228) has noted: 'assessment data gathered... are only helpful in improving instruction when teachers are willing to modify their practices based on the data'. Such modifications are also only likely when the assessment focus is on more than just the grades that students receive for particular pieces of work. 


\section{The study}

The case study school, Red Point High School was one of two co-educational government secondary schools located in a regional area in the Australian State of Queensland that participated in a large study of the ways in which teachers enacted socially just practices in their classrooms ${ }^{\text {vii }}$. Central to the case study school's original willingness to participate in the study had been the medium grading that they received on differentiation during the Teaching and Learning Audit. Red Point caters to approximately 2000 students who are generally from middle class backgrounds - it has a small, but reasonably large for an urban school, Indigenous population (6\%) and a small percentage of students whose language background is other than English (4\%), but students are predominantly of AngloAustralian heritage. Red Point has a strong reputation for academic excellence and, especially during our early visits to the school, indicated a pride in its private school image and high standards of behaviour.

The study lasted for three years and involved eight visits to the school between 2011-13. We conducted interviews with eleven teachers, and a range of other school personnel, for example the principal, deputy principals, Indigenous liaison officers, and students. Most people were interviewed multiple times. The interviews were loosely structured around a series of focus prompts that sought to explore each participant's role at the school, their thoughts about the school and its students, their understandings of social justice in general, and of differentiation more specifically, their thoughts on the key enablers and constraints to creating classrooms that were conducive to all students receiving a high quality education. We also conducted classroom observations and ran workshops, with teachers participating in the study for feedback on our findings. Thus, in addition to interview data, we also used data collected from teachers during these workshops.

That differentiation was a focus of the school was well known by most of the teachers that we were working with. A number of teachers indicated that the emphasis on differentiation that had occurred around the Teaching and Learning Audit had seemed overwhelming, but that the dialogue 
that they had had since had eased their fears. However, some of the teachers were unaware of the Teaching and Learning Audit process. They saw that the pressure to differentiate their classes was coming from the principal. The audit outcomes appeared to have had more of an effect upon the principal; this might be because principals felt that the outcomes reflected upon their leadership.

As a consequence of this concern with what was happening in the classrooms the 17 person leadership team at the school (heads of department, deputy principals and the principal) were each allocated four classes to visit and observe. They were to collect data on a range of practices with a focus on student engagement. We were told: 'that will all get collated on a spreadsheet to get a sort of snapshot of a week at Red Point.' What was apparent was that part of this information was being sought to ensure that the principal could meet his accountability expectations. For instance, he indicated that if he was asked if he knew whether or not the Australian Curriculum ${ }^{\text {viii }}$ was being implemented in his school, 'I could say 'OK, it's been implemented', but 'how do I know?' 'Because I've gone into classes.". However, the class visits were not solely about ensuring that teachers were conforming to various mandates, they were also seen as having a role in creating professional dialogue as after each observation there was a meeting between the staff member and the leadership team member about what had been seen in the classroom.

Whilst the audit had led to this increased surveillance of teachers, it also led to changes in the organization of staff meetings. It was reported that every second staff meeting was now devoted to professional dialogue and in-service on a number of educational topics, including behaviour management and using data. Discussion was seen as being critical to improving practice. It was at these staff meetings where differentiation had been discussed by the whole staff. At one of these meetings differences in understandings between various faculties had been foregrounded. For instance, we were told that it was apparent that there were people in the Arts Faculty who had been doing differentiation 'forever': 'They've got - like, in visual art,- or in music - you know, they're basically designing their own art work, choosing what medium they want to use. There's so much 
capacity for individualized and personalized learning.' On the other hand, there were some faculties where there was significant resistance to differentiation, the mathematics department was highlighted as one of those.

In this paper we foreground data from five of the twenty school personnel interviewed at Red Point: the principal ('Phil'), and key teachers, 'Lucy' (Head of drama), 'Florence' (Head of English), 'Mary' (drama teacher) and 'Sonia' (social science, literacy and numeracy teacher). These voices appear here because they seem to encapsulate the key issues that were salient at the school in relation to differentiation: issues of grouping and individualization and streaming in relation to pedagogical differentiation and issues of individualisation in relation to assessment. Such salience informed our analysis of the interview data in terms of identifying the key and emerging themes - a salience that was informed by the literature reviewed earlier. Given our concerns with the reportedly 'perverse' effects of the audit culture in relation to constraining pedagogical differentiation within contemporary schools, our analysis then turned to a focus on how this culture intersected with teachers' concerns about and practices in relation to differentiation. We acknowledge that the findings presented here may be seen as limited in their derivation from a single case study in a regional area of Queensland. We present these findings as illustrative of how global audit trajectories are currently being played out at a local school level. Beyond the parochial, these findings as they are associated with issues of differentiation share distinct resonance with, and relevance to, key international debates and concerns about how the audit culture is currently delimiting school practice - especially in relation to the production of teacher anxieties and the undermining of social justice (see Ball, 2003). The findings around issues of differentiation and pedagogical reform presented here provide further and important insight into the complexity and nuance of these issues. 


\section{Findings}

There are a number of important findings that emerged from our study in relation to the way in which differentiation was taken up at the school level. These findings relate to how differentiation was interpreted and implemented, and to the way in which issues of pedagogical reform in general were implemented. In the first instance it became apparent that the term differentiation was not well understood by many of the teachers who we were working with. This was recognized by the new principal who was critical of some of the existing practices at the school, in particular its approach to streaming. However, it was also apparent that there had not been a lot of support by the state department of education to ensure that there was widespread understanding and take up of differentiation. Instead the primary mechanism for ensuring that differentiation was on the agenda in schools was by including it in the Teaching and Learning Audit. This had the effect of putting pressure on principals, who were ultimately held accountable for the audit results, to ensure that teachers were differentiating within their classrooms. We begin this section of the paper here with a consideration of teachers' understandings of differentiation and then conclude with the ways in which the school responded to the audit expectations.

\section{Understandings of differentiation}

One of the main features of the case study school's interpretation of differentiation had been to equate it with streaming classes or setting up mixed ability groups within classes. It was suggested that the school's approach to streaming under the previous principal had been instrumental in its good outcomes and that differentiation was supportive of this approach. Red Point has not been alone in considering 'ability grouping' as a means of lifting academic standards (Ireson \& Hallam, 1999); nor indeed in seeing differentiation as another term for streaming. For example, Terwell (2005, p.653), in his work on 'curriculum differentiation' writes 'curriculum differentiation, i.e. streaming, tracking, ability-grouping, is one of the most persistent issues in curriculum theory and 
practice'. Interestingly this view tended to be held by teachers rather than the principal. Indeed the principal was highly critical of this association. Phil claimed for instance:

And I think probably for too long people here have felt we're differentiating because we've got basically streamed classes. That's not differentiation.

His view was that differentiation involved diverse ability, or heterogeneous, classes where the teacher set activities to meet the needs of all the students He told us:

Differentiation is 'in my class of 25 ... I've got 25 different kids with different abilities and making sure I've got learning tasks happening that are appropriate to their needs. It's hard work - no doubt it's the hardest aspect of teaching, I think.

He went on to explain what this might look like in the classroom. He described a hypothetical class where differentiation would be occurring. In this class of 25 students he envisaged the 'high flyers' undertaking independent work, whist the teacher worked with other groups of students who were struggling, and a teacher's aide supported individuals or very small groups who had trouble with their reading. He stressed that these groups would not be fixed, but 'fluid': 'It shouldn't be locked in to, you know, this person is always going to be in that middle group, or the lower group.' He suggested that there were not many teachers in the school who were interpreting differentiation in this way.

What was apparent in working with a group of teachers in the school was that they felt uncertain about what was expected of them in relation to differentiation. One teacher in particular, Lucy, told us how as part of her trial and error approach to implementing differentiation she had tried three different types of groups. In the first instance, she broke the class into groups on the basis of current achievement levels. She explained that this meant that:

I was almost writing for five different classes every time I had a lesson with those kids... I tried that for a week - and I ended up spending the majority of my time with my low level kids, 
because they need so much structure and assistance and help to get through even minimal tasks. And I almost felt guilty because I was neglecting my high end kids, because they are capable of doing things on their own. But when Samara said to me on the way out 'I felt like I haven't seen you for a week, Miss', I thought right, it's got to go, it's not working that way...

This had a big impact upon Lucy, as, she told us, Samara was 'probably my top kid'. She noted that it had not been a conscious decision to leave the high achiever groups on their own, 'but that's how it happened, just because the other kids were more needy'. As a consequence of not being able to support many of the students in the class because of the amount of time she was spending with the students who needed the greatest support in the classroom, she then set up mixed ability groups.

So then I tried mixed ability groups. ... I felt like that failed as well, because the kids relied really heavily on who the B kids were.

Lucy had hoped that the 'peer coaching' that could take place within this structure would be a great benefit to both the high and lower achieving students in the groups. However, she suggested that the different motivation levels and the willingness of the lower achieving students to defer to those obtaining better grades than them meant that the quality of learning was affected. As a consequence she claimed:

I felt like they learnt nothing in that week, that I tried mixed ability. Because they were just copying either - or agreeing, or being apathetic about the decisions that were being made. The third form of grouping that she tried was based on friendships. She indicated that: 'That was probably the most successful grouping that I had for that class.' She suggested that within friendship groups the students had close relationships with each other and strong commitments to making sure that the group dynamics worked. She explained that this might have been because she set tasks that had to be completed before students were allowed to leave to go out to recess. Thus when asked why she thought it had been so successful she replied: 'Only because I think they generally care 
about each other enough to want to help each other to get out the classroom at the time - that's the motivation.' However, there did also appear to be other factors. She talked about how she also changed her classroom activities with the new friendship groups in order to make the class work more engaging:

...it wasn't a concrete sheet that had to be done, or a concrete activity, or a table that had to be filled out - like, there had to be genuine discussion and that had to be - they had to decide, and make opinions, and make judgments... And I knew that I could do conversationy type stuff with those groups, because they're already used to conversing and they already respect each other. But if I tried to do that in, say - I don't know - mixed ability groups, I can't see that they would value each other's opinions...

She also indicated that the first two forms of grouping were resented by the students who did not want to be told which groups that they had to belong to. This aligns with those arguments by Tomlinson and others that a lack of student voice in the classroom has an impact upon their motivation and engagement in class.

In contrast to the grouping of students, another way in which differentiation was interpreted was as a need to construct individual learning plans for every student. In terms of high school teaching, this meant that teachers could have to prepare up to 150 different plans! This situation came up with the teachers at one of our group meetings. Florence, a teacher who had been extremely enthusiastic about differentiated learning, argued to the group that teachers should have individualized work plans and that was what she had for every one of her students. She told us during a group discussion why she was prepared to do this:

Because I feel very strongly about all my kids having opportunities to succeed in everything and so I just feel very happy about it. I do spend a lot of hours working but, that is my goal to have individualized learning plans for all of my students and ... I do think it is possible. 
Many of the other teachers appeared incredulous at this claim, and indeed due to her perceived expertise on differentiation became highly critical of such expectations. However, this view of differentiation was not shared by the principal. Phil told us:

It's a tough ask to say there's 25 different kids in the class - everyone gets an individualized programme....I mean that's just bizarre. Like, you know, the workload would be ridiculous.

It was not only in relation to the ways in which students were grouped in class or surrounding the appropriateness of individualized learning programmes where there was confusion amongst teachers. Assessment in relation to differentiation was also raised as a contentious issue. For some teachers differentiation meant trying to construct different assessment tasks to ensure that students could achieve success and provide them with an opportunity to demonstrate their strengths rather than their weaknesses. Some teachers were upset that they had been told that they were not allowed to change assessment tasks for different groups of students. Lucy who had been enthusiastic in her engagement with differentiation, told us:

I think that's the key ingredient - being able to change the assessment piece, so that every single kid is able to - you're able to better reach every single kid. Like l've got kids in my low level grade 10 class that can't write an essay, but they'd do an amazing play script if I was able to. ... I think there's always going to be some reason, and some situations, where kids have to learn to write an essay $-\ldots$ but being able to change some of the assessment pieces, some of the time, would be really, really handy....

Another teacher commented:

Mary: I'd love nothing more to have than levels in my assessments constantly so that every time, every assessment it was differentiated so that kids could pick even the mode of delivery... I'd like to differentiate every assessment to have at least three levels for my Grade Ten class, but, we're not allowed to in English... 
This policy appeared to vary across the different curriculum areas. Within mathematics in the nonsenior years teachers suggested that the assessment tasks catered to different levels. However, this appeared to relate to such practices as extension tests for the high achieving mathematics students. In the main the policy in each department in the school appeared to be that there was a common assessment system that all students participated in.

There was also discussion about the extra support students were entitled to in order to complete assessment tasks, especially exams. One teacher, Lucy, was quite cross that such support was limited to those students who had been ascertained or who were deemed to be English as a Second Language (ESL) student. She stated: 'I just hate that kids only get extra support if they've been officially labeled with something.' During the same discussion, another teacher went on to raise concerns about her students who she knew would struggle with the demands of exams:

Sonia: You see them sitting in exams because we have to go and supervise them and there are so many kids that are in our literacy, numeracy classes that we know would benefit just by someone (a support teacher) being there in the exam room and they're not allowed to and every year we ask if we could please have these kids come and sit in a supervised class with us and they say 'no' every single time.

For some of these teachers, a failure on the part of some departments to differentiate through extra support for those students who were clearly struggling at school was seen as an equity issue that was not being addressed at the school.

What is evident from these short excerpts is that some teachers, like Lucy, are clearly grappling with differentiation in the classroom. Whilst others, like Florence, have very firm ideas about what constitutes differentiation, but that view is not shared by other teachers, or indeed by the principal, who by having been selected to be an auditor was deemed to be an expert on differentiation. There were even tensions across departments with very different responses to issues such as 
differentiating assessment tasks. The uncertainty surrounding the meaning of differentiation would seem to highlight the difficulty schools faced in obtaining an 'outstanding' on this aspect of the Teaching and Learning Audit.

These data add to the argument made earlier that differentiation needs more theoretical and practical definition and teachers need more support to explore this in their work. One interesting side story to our study is that had the school not performed poorly on the Teaching and Learning Audit in relation to differentiation we might not have been given the opportunity to work with these teachers, which in turn provided them with space to trial various approaches to differentiation in their attempts to understand its purposes and practicalities. We recognize that not every teacher is in the position of those at Red Point in that they can be provided with space to work closely with academics to engage in professional dialogue about a particular reform. However, we would stress that it is these very conversations that are critical to pedagogical reforms that can benefit students.

\section{Analysis/conclusion}

There is much to be concerned about in relation to the 'audit culture' that is shaping practices in schools (see for example, Apple, 2005; Grek et al., 2009; Keddie et al., 2001). The various quality assurance mechanisms that constitute this culture are affected by local contexts (see for example, Keddie, 2013). However, as Ball (2003) has argued, this culture has created high levels of anxiety for many teachers as they attempt to make sense of the different ways in which they are being assessed and judged through various auditing processes. This was the case at Red Point High School. The way in which teachers at Red Point High School took up the mandate of differentiated learning, as prescribed in the Queensland Teaching and Learning Audit, offers a number of lessons about both differentiation and pedagogical reform and their impact upon teachers. There are clearly different understandings and mobilisations of differentiation amongst teachers, by the school administration and across different faculties in the school. These different understandings are shaped and informed by the audit culture operating in Queensland government schools. To some extent this culture has 
inhibited socially just practices in schools as narrow forms of differentiation based around streaming and setting have been implemented. There is also a way in which the increased surveillance of teachers can work towards them taking 'safe' options rather than attempting significant reforms. However, some of the teachers' stories at the school indicate that when freed from top-down policy approaches that come with punitive/surveillance measures, possibilities for a richer engagement with the underpinning rationale for those policies occur.

Through these discussions it became apparent that differentiation, as represented by pedagogical, or instructional differentiation, can align nicely with a social justice agenda in schools. For instance, it is concerned with ensuring that all children are challenged intellectually in the classroom, that teachers take into account student background to ensure that the learning is meaningful, encourage active learning and create spaces for student voices to be heard, and that student differences are respected and taken into account. However, the ways in which the push for differentiation is legitimising the streaming of classes, as was the case in some sections of the case study school, is a cause of concern. The inequities with such practices have long been identified (see for example, Ireson \& Hallam, 1999), and indeed many advocates of pedagogical differentiation are often highly opposed to streaming (see for example, George, 2005). Unfortunately, as Boaler argued back in 1997 (p.165), greater competition between schools, marketization and league tables has 'meant that setting is now back in vogue and schools are returning to policies of differentiation and polarization... in alarming numbers'. It is quite possible that pressures around the Teaching and Learning Audit will ensure that such streaming setting practices are still seen as the appropriate way to differentiate.

The individualized approach to differentiation, sometimes seen as a counterpoint to streaming, raised by one of the teachers at the school is also questionable as an effective and appropriate response to differentiating a classroom. Individualized programs in high schools are problematic on at least two levels. First, as recognized by the principal, it is a workload issue for teachers. Whilst we 
would suggest that it is important for teachers to know their students and to try and understand the ways in which they can be stimulated and motivated to learn, an individual program for every student when a teacher might have up to six different classes is almost impossible to create. Secondly, and perhaps a more serious concern, is the way in which problems with learning can be individualized. Increasingly disadvantage is seen as an individual problem rather than as a problem created through systemic or structurally driven inequities and injustices. With this view, oppressions brought about through, for example, differences in gender, race, ethnicity, class, sexuality and age are often washed out of pedagogical considerations. When this occurs, group identity, or indeed solidarity, is not encouraged. We would suggest, as indeed much of the differentiation literature does (see for example, Jackson, 2005; de Jager, 2013), that students from marginalized backgrounds will benefit from having their cultures valued in the classroom, and that those from more privileged backgrounds will also reap the benefits from pedagogical practices that expose them to rich and diverse forms of knowledge and understandings about the world.

We are also concerned, as were some of the teachers in our study, that differentiation might lead to a watered down curriculum and low expectations of students, especially if assessment tasks offered differing levels of intellectual challenge. We are of the view that differentiating learning and assessment in a classroom can still be challenging and meaningful (de Jager, 2013). Here we think of the assessment literature which suggests that students be provided with real world problems that are related to student interests (see for example, Hayes et al., 2006). As we have indicated earlier, we would suggest that what should be of concern to educators is finding ways for students to showcase their learning. This might mean that some students are given extra time, extra resources and support, have input into the construction of tasks, and have a range of choice about how to present their knowledge, skills and understandings. However, the expectations around quality should not be different. 
One positive contribution of the audit had been that the school had begun discussions around pedagogy, this was apparent in the staff meetings and in the conversations after visits to teachers' classrooms by the school leadership team. However, much of this had a substantial aspect of surveillance to it. We, as was the case with many of the participating teachers in our study, are not opposed to accountability in that we do think that teachers need to be held accountable for the ways in which they approach their teaching and their students. However, there is sufficient literature to suggest that narrow forms of accountability can lead to teachers (and schools) 'fabricating' an image that best meets what are perceived to be the requirements of prevailing discourses (see Ball, 2003; Keddie, Mills \& Pendergast, 2011). In the case of differentiation, where there is a lack of knowledge about what it entails and where there is pressure from an audit and classroom visits from a leadership team (some of whom were identified by teachers as also not having a good understanding of differentiation), the responses appeared to lack substance. Indeed in our many observations of classes we were struck by the lack of active learning, by a lack of engagement with difference and young people's backgrounds and cultures, and indeed the lack of intellectual quality. However, we also came across many thoughtful teachers who cared about their students, and who put a lot of effort in to the preparation and delivery of their classes. It very much appeared that this lack of pedagogical differentiation was not due to any deficit in the teachers, but in the failure of the system to create the appropriate environment for them to enact and trial the forms of pedagogy that align with differentiation. Hence, a 'perverse effect' (Lingard \& Sellar, 2013) of Queensland's Teaching and Learning Audit may well be that whilst bringing differentiation as a term into discourse at the school, the effect of the audit on the culture of the school meant that many teachers did not have time to develop deep understandings of what it would mean to differentiate their classrooms and fell back on what they knew best, streaming, setting, individualized plans and different quality tasks. 
As is apparent here differentiation is a complex concept, not easy to shift from policy to classroom context, and perhaps requires more careful explication at policy level and more support for teachers to enact. We would also suggest that for worthwhile innovations to reach classrooms through policy, teachers need to be convinced of their merit. Teachers are unlikely to acquire this conviction when simply compelled to implement reforms. As teachers in our case study demonstrated, when given the space to experiment with a particular pedagogical strategy, in this case differentiation, many teachers are very willing to work in productive - learner responsive - ways to see how it might best meet the needs of their students.

\section{References}

Apple, M. (2005) Education, markets and an audit culture, Critical Quarterly, 47(1-2), 11-29.

Ball, S. (2012). Global education Inc.: new policy networks and the neo-liberal imaginary. London, Routledge.

Ball, S. (2003). The teacher's soul and the terrors of performativity. Journal of Education Policy, 18(2), 215-228.

Black, P., Harrison, C., Lee, C., Marshall, B. \& Wiliam, D. (2003). Assessment for learning: putting it into practice. Maidenhead, UK, Open University Press.

Chilcott, T. \& Helbig, K. (2012). Queenslanders want school audit results published, The Courier-Mail February 01, http://www.couriermail.com.au/news/queensland/queenslanders-want-school-auditresults-published/story-e6freoof-1226259006071 accessed 7/3/2013.

Chilcott, T. (2012) Report card: How your school stacks up, The Courier-Mail, January 28, http://www.couriermail.com.au/news/queensland/report-card-how-your-school-stacks-up/storyfnbwroq7-1226255868681 accessed 7/3/13. 
Coldron, J., Cripps \& Shipton, L. 2010 Why are English secondary schools socially segregated? Journal of Education Policy, 25 (1), 19-35.

Department for Education (DfE) (2010).Teachers'Standards. London, Her Majesty's Stationary Office (HMSO).

Grek, S., Lawn, M., Lingard, B. \& Varjo, J. (2009) North by northwest: Quality assurance and evaluation processes in European education, Journal of Education Policy, 24(2), 121-133.

Ireson, J. \& Hallam, S. (1999). Raising standards: is ability grouping the answer?, Oxford Review of Education, 25(3), 343-358.

Jackson, Y. (2005). Unlocking the Potential of African American Students: Keys to Reversing Underachievement, Theory Into Practice, 44(3), 203-210.

Keddie, A. (2013). Thriving amid the performative demands of the contemporary audit culture: A matter of school context, Journal of Education Policy, DOI: 10.1080/02680939.2013.768706

Keddie, A., Mills, M. \& Pendergast, D. (2011). Fabricating an identity in neo-liberal times: performing schooling as 'number one', Oxford Review of Education, 37(1), 75-92.

Klenowski, V. (2011). Assessment for learning in the accountability era: Queensland, Australia, Studies in Educational Evaluation, 37(1) 78-83.

Kronborg, L. \& Margaret Plunkett, M. (2008). Curriculum differentiation: an innovative Australian secondary school program to extend academic talent, The Australasian Journal of Gifted Education, 17(1), 19-29.

Laitsch, D. (2013). Smacked by the invisible hand: The wrong debate at the wrong time with the wrong people, Journal of Curriculum Studies, 45(1), 16-27. 
Lingard, B. Mills, M. \& Hayes, D. (2006). Enabling and aligning assessment for learning: some research and policy lessons from Queensland, International Studies in Sociology of Education, 16(2), 83-103.

Lingard, B. (2010). Policy borrowing, policy learning: Testing times in Australian schooling, Critical Studies in Education, 51(2), 129-147.

Lingard, B., \& Sellar, S. (2013). 'Catalyst data': perverse systemic effects of audit and accountability in Australian schooling. Journal of Education Policy. iFirst doi: 10.1080/02680939.2012.758815

Masters, G. (2009). A Shared Challenge: improving literacy, numeracy and science learning in Queensland primary schools, The Australian Council for Educational Research, Camberwell, Victoria. Masters, G. (2010). Teaching and Learning: school improvement framework. State of Queensland (Department of Education and Training) and the Australian Council for Educational Research (ACER). McTighe, J. \& Brown, J. (2005). Differentiated instruction and educational standards: is detente possible?. Theory Into Practice, 44(3), 234-244.

Moon, T. (2005). The role of assessment in differentiation. Theory into Practice, 44(3), 226-233.

Newmann, F. \& Associates (1996). Authentic achievement: restructuring schools for intellectual quality. San Francisco, CA, Jossey-Bass.

Noble, T. (2004). Integrating the revised Bloom's taxonomy with multiple intelligences: a planning tool for curriculum differentiation. Teachers College Record, 106(1), 193-211.

OECD (2005). School factors related to quality and equity, Results from PISA 2000. Retrieved from http://education.qld.gov.au/literacy/docs/quality-equity.pdf.

Perryman, J. (2006). Panoptic performativity and school inspection regimes: disciplinary mechanisms and life under special measures. Journal of Education Policy, 21(2), 147-161. 
Power, M. (1999) The audit society: Rituals of verification. Oxford, Oxford University Press.

Stobart, G. (2008). Testing times: the uses and abuses of assessment. New York, Routledge.

Subban, P. (2006). Differentiated instruction: a research basis. International Education Journal, 7(7), 935-947.

Swaffield, S. (2011). Getting to the heart of authentic assessment for learning. Assessment in Education: Principles, Policy \& Practice, 18(4), 433-449.

Terwel, J. (2005). Curriculum differentiation: multiple perspectives and developments in education, Journal of Curriculum Studies, 37(6), 653-670.

Tomlinson, C. (1995). Deciding to differentiate instruction in the middle school: one school's journey. Gifted Child Quarterly, 39(2), 77-114.

Tomlinson, C. (1999). Mapping a route toward differentiated instruction. Educational Leadership, $57(1), 12-16$.

Tomlinson, C. A. (2000). Reconcilable differences. Educational Leadership, 58(1), 6-11.

Tomlinson, C. A. (2005). Grading and differentiation: paradox or good practice?. Theory into Practice, 44(3), 262-269.

Tomlinson, C. A. (2008). Goals of Differentiation. Educational Leadership, 66(3), 26-30.

Torrance, H. (1995). (Ed.) Evaluating authentic assessment: problems and possibilities in new approaches to assessment. Buckingham, UK, Open University Press.

\footnotetext{
' Office for Standards in Education, Children's Services and Skills, School Inspection Framework, http://www.ofsted.gov.uk/resources/framework-for-school-inspection.

ii National Assessment Plan - Literacy and Numeracy. Australia's national annual standardised tests of years 3, 5, 7 and 9 students.
} 
iii Programme for International Student Assessment. International tests, sponsored by the OECD that seeks to evaluate education systems worldwide. It is conducted every three years and assesses 15-year-olds' competencies in: reading, mathematics and science. See http://www.oecd.org/pisa/.

iv The My School website, http://www.myschool.edu.au/, is sponsored by the Australian Curriculum, Assessment and Reporting Authority (ACARA), and provides information about every school in Australia including results on NAPLAN.

${ }^{\vee}$ Pseudonyms are used for all places and people related to the case study.

vi These include: An Explicit Improvement Agenda; Analysis and Discussion of Data; A Culture that Promotes Learning; Targeted Use of School Resources; An Expert Teaching Team; Systematic Curriculum Delivery; Differentiated Classroom Learning; and Effective Teaching Practices (Master, 2010).

vii This article reports findings from the 2010-2012 Australian Research Council Discovery Project (DP1093082) 'Engaging students: Issues of difference, distribution and recognition in schools'. The Chief Investigators were Martin Mills, David Geelan, Peter Renshaw, Amanda Keddie and Pam Christie. Sue Monk was Project Manager and Christina Gowlett a Research Fellow (2012). The views in this paper represent those of the named authors only.

viii The Australian Curriculum is Australia's first national curriculum and is being phased into the States at different rates. In 2012 Queensland introduced the English, Mathematics and Science curricula, History was introduced in 2013. See http://www.qsa.qld.edu.au/9188.html. 